๑ Laboratorium: журнал социальных исследований. 2020. 12(2):277-282

DOI: $10.25285 / 2078-1938-2020-12-2-277-282$

\title{
Олеся Кирчик
}

\section{Mario Biagioli and Vincent Lépinay, eds. From Russia with Code: Programming Mi- grations in Post-Soviet Times. Durham, NC: Duke University Press, 2019. 384 pp. ISBN 978-1-4780-0299-4.}

Олеся Кирчик, Национальный исследовательский университет «Высшая школа экономики» (Москва). Адрес для переписки: НИУ ВШЭ, Старая Басманная, 21/4, корпус A, каб. 314-318, Москва, 105066, Россия. okirchik@hse.ru.

Рецензируемая книга написана коллективом по большей части молодых исследователей, принявших участие в «мегагранте» по изучению российских программистов на базе Центра исследований науки и технологий Европейского Университета в Санкт-Петербурге. Руководителями проекта и редакторами монографии стали известный специалист в области STS Марио Бьяджоли (Калифорнийский университет) и Венсан Лепинэ, сотрудник созданного Бруно Латуром Medialab (Институт политических наук в Париже). Образовательная и профессиональная траектории многих участников проекта также связаны с западными университетами и исследовательскими центрами. Иначе говоря, академические миграции стали не только предметом, но и условием реализации самого проекта «From Russia with Code». Вместе с тем тематические рамки книги намного шире, чем заявленные в названии профессиональная мобильность и диаспоры российских программистов за рубежом. Собранные в книге тексты вступают в диалог с социальными исследованиями предпринимательских культур (Yurchak 2002), профессиональной идентичности и инфраструктуры (в широком смысле - от образовательных структур и практик до технопарков и «хакерспейсов»), а также гражданского участия (онлайн-активизма) в современной России и в меньшей степени заняты компьютерными технологиями и инновациями как таковыми (Бычкова и др. 2019). Редакторы книги определяют жанр своего коллективного исследования как multi-sited ethnography разнородного конгломерата «IT-акторов», который трудно назвать «профессией» в прямом смысле слова и который авторы, к сожалению, не концептуализируют более четко.

Помимо предполагаемого вмешательства России в американские или французские президентские выборы, а также некоторых других скандалов с участием российских IT-компаний и «хакеров», попавших в фокус внимания западных масс-медиа, российские «программисты» представляют несомненный исследовательский интерес по нескольким причинам. Во-первых, это, пожалуй, наиболее заметный среди немногих успешных наукоемких секторов экономики, не связанных с извлечением природных ресурсов и в наименьшей степени обязанных своим успехом (во всяком случае до недавнего времени) государственной поддержке. Во-вторых, это один из немногих высокотехнологичных секторов, участвующих в мировом рынке - пускай не наравне с ведущими IТ-игроками. Тем не менее, он поставляет популярные и даже лидирующие в своих нишах продукты (антивирусный софт от KaseprskyLab, язык программирования Kotlin и др.). Нако- 
нец, Россия является одной из немногих стран, где национальные аналоги способны конкурировать или даже потеснить доминирующие в мире сервисы («Яндекс», «Мэйл.ру» и проч.), обеспечивая определенную киберавтономию страны и влияние в русскоязычном интернет-пространстве.

Авторы книги нередко ссылаются на «миф» о русском программисте и хакере, определяющий профессиональную идентичность и репутацию этих специалистов внутри и за пределами страны. При этом, говоря словами редакторов монографии, российскую компьютерную науку и индустрию характеризует «ambivalent excellence» («сомнительное превосходство»), поскольку России пока плохо удается реализовать имеющийся научно-технический и человеческий потенциал в виде преимущественно инновационной структуры экономики и стабильно работающих бизнесов, все еще занимающих в ее совокупном продукте не слишком высокое место. Через всю книгу проходит вопрос о том, является ли внушительное советское наследие (сильная математическая школа, массовое техническое образование, популяризация кибернетики и компьютерной грамотности и т. д.) преимуществом или «проклятием» современной IT-индустрии, будучи одновременно важным фактором относительных неудач последней во внедрении и коммерциализации разработок?

Название книги («Из России с...») обыгрывает название известного шпионского фильма, одновременно намекая на то, что «российский программист» - это такой же стереотип, как и другие клише Холодной войны. На самом деле этот образ является порождением определенного исторического периода в той мере, в какой компьютеры и информационные технологии были одной из значимых ставок в противостоянии и соревновании двух сверхдержав. И хотя линия преемственности современной IT-индустрии с советскими кибернетикой и информатикой оказывается значимой для общей проблематики книги, собственно советскому периоду посвящена лишь ее первая глава (Ксения Татарченко ${ }^{1}$ ). В главе дается набросок истории развития компьютеров и программного обеспечения в Советском Союзе с конца 1950-х годов. В отсутствие исчерпывающей или хотя бы неполной, но систематической историографии этой научно-технической сферы здесь кратко представлены некоторые ключевые институции и фигуры раннего периода, связанного с появлением первых советских компьютеров и программ. На примере группы академика Андрея Ершова в Вычислительном центре (ВЦ) новосибирского Академгородка прослеживаются некоторые сквозные для последующих глав темы - международные циркуляции и интеграция в международные сети и проекты, рождение профессиональной идентичности программиста и легитимация новой профессии в начале 1970-х годов. Мы также узнаем, что Ершов был автором концепции формирования с детства «алгоритмического мышления» и одним из деятельных сторонников введения «основ информатики» в советских школах начиная с 1985 года.

1 Ксения Татарченко - специалист по истории компьютерной техники в СССР (Tatarchenko 2013). 
Итог советской «компьютерной революции» оказывается, по мнению автора, неоднозначным. С одной стороны, в брежневском СССР была создана вполне конкурентоспособная и интернационализированная компьютерная наука (достаточно вспомнить успех компьютерной программы «Каисса», занимавшей первое место в международном конкурсе шахматных программ), с другой же стороны, не были решены проблемы профессионального образования и статуса программиста (вследствие чего в профессии преобладали представители «ненадежной» рабочей силы - женщины и евреи). Были заложены образовательные традиции в программировании (в том числе летние школы, компьютерные клубы), однако в школах было недостаточно компьютеров, учебников и квалифицированных учителей. Была создана компьютерная промышленность, но не удавалось производить компьютеры в достаточном количестве, выпускавшиеся модели были невысокого качества и не могли конкурировать с американскими аналогами. Наконец, можно отметить высокий интерес к компьютерам в позднесоветском обществе, который «компенсировался» отсутствием ПК в домах советских граждан и в целом, по мнению автора, провалом СССР в решении задачи вхождения в «информационную эру». Расхожим аргументом здесь выступают особенности плановой экономики и партийного идеологического контроля. Такого рода всеобъемлющие объяснения, очевидно, должны быть дополнены и детализированы благодаря систематическим исследованиям, коим еще только предстоит появиться.

Тем не менее, книга намечает возможность отхода от однозначных, идеологически мотивированных ответов на парадоксальный вопрос, который можно назвать главной «интригой» всей работы: «Is failure the only way to describe late Soviet [and consequently, post-Soviet] computer developments?» (с. 51). При этом тезис о «неудаче» принимается на веру без серьезного обсуждения критериев. Сама постановка вопроса отражает распространенную тенденцию рассматривать кейсы, отклоняющиеся от нормативного образца (как правило, «англо-американской» науки и индустрии), в бинарных терминах. В действительности же картина выглядит сложнее и нюансированнее.

Так, например, Андрей Индукаев в главе 7, посвященной постсоветскому развитию IT-сектора в Сибири на примерах Новосибирска и Томска, полемизирует с известным американским историком советской науки Лореном Грэхэмом (Lauren Graham), который объясняет систематические неудачи работающих в сфере высоких технологий русских предпринимателей в том, что касается превращения научных идей в доходные технологические инновации, их негативным отношением к любой форме коммерческой деятельности. Это является, по мнению историка, одним из следствий непреодоленного советского наследия (с. 195). На основе полевого исследования Индукаев, напротив, утверждает, что сибирские IT-предприниматели способны успешно вести бизнес и выработали собственную бизнес-стратегию, которая, однако, отличается от логики стартапов и венчурного капитала (сочетающей высокие риски с потенциально сверхвысокими прибылями), к которой как к некоему идеальному типу обычно аппелируют Грэхэм и другие исследователи (с. 196). Понеся значительные потери человеческого капитала сразу после распада Советского Союза, Новосибирск и Томск тем не менее смогли 
создать успешно функционирующие, ориентированные в основном на международный рынок инфраструктуры, связывающие подготовку кадров, разработку и коммерциализацию информационных продуктов. Как и в других рассмотренных в книге кейсах, здесь оказывается, что современная образовательная и профессиональная IT-инфраструктуры региона во многом продолжают созданный в советский период паттерн, включая специализацию на программных продуктах определенного типа. В тексте Дмитрия Жихаревича (глава 9), показано, что лидеры российской IT-индустрии (например, известные международные компании АBBYY, KaseprskyLab и другие) также формировались на базе позднесоветских научнопроизводственных структур.

Одной из важных сквозных для книги тем является проблема создания благоприятной инвестиционной и городской среды для ведения IT-бизнеса в постсоветской России. В нескольких главах (часть 2) оцениваются последствия предпринимаемых российским правительством в этом направлении усилий с середины 2000-х годов. Эти усилия выразились в основном в создании технопарков, бизнес-инкубаторов и особых экономических зон с целью привлечения российских и иностранных инвестиций, в том числе в сферу информационных технологий. В главе 4 Александры Масальской и Зинаиды Васильевой прослеживается постсовесткая эволюция IT-предпринимательства во Владивостоке. Из этого информативного и рельефного описания кейс-стади (которое можно считать большой удачей авторов) мы узнаем о том, что в 1990-е годы IT-фирмы здесь были неразрывно связаны с бизнесом по импорту подержанных японских автомобилей; о том, как усилиями энтузиастов сохранялись традиции компьютерного образования и, наконец, как развивались продуктивные и взаимовыгодные связи между университетом и бизнесом, которые характеризовали технологическую сферу этого региона до второй половины 2000-х годов. Осуществляемая с этого времени федеральным центром «инновационная» политика вкупе с кризисом 2008 года и другими макроэкономическими факторами имела, по оценке авторов, разрушительные последствия для локального бизнес-сообщества. Другие попытки создания инновационной экосистемы по принципу top-down, рассмотренные на примерах казанского Иннополиса (Алина Контарева, глава 5) и Сколково (Александра Симонова, глава 6), также ставят под сомнение возможность «искусственного» создания «силиконовых долин» по инициативе федеральных и региональных властей. Ожидания и потребности бизнеса оказываются несовместимы с бюрократической логикой - начиная от локализации технопарков (вне динамичных и более доступных с точки зрения транспортной инфраструктуры городских центров) и заканчивая излишней централизацией и иерархичностью созданных структур. На примере Татарстана и Эстонии (Дарья Савченко, глава 8) проблематизируется политическое использование IT в качестве регионального или национального бренда. Среди представленных в книге кейсов сибирский случай выглядит в этом отношении наиболее успешным, что может быть объяснено присутствием там сильного местного, уходящего корнями в советское прошлое, бизнес-сообщества, которое способно вести переговоры по поводу навязываемых извне инструментов инновационного развития. 
Неслучайно в фокус авторов рецензируемой книги нередко попадает понятие coобщество (community) -при анализе как факторов (не)успешного функционирования IT-бизнеса, так и (не)успешной интеграции программистов в случае иммиграции. Профессиональное обучение и социализация оказываются ключевыми параметрами в создании общности (сравните с более традиционными научно-техническими дисциплинами, для которых ключевым является цикл университетского образования и подтверждение его успешного завершения в виде дипломов и степеней). Так, на примере «Яндекса» рассматриваются практики обучения новых сотрудников on the job, в первую очередь связанные с чтением кода, для создания специфической профессиональной идентичности и community (Марина Федорова, глава 2). Особенно интересен в этом отношении случай Израиля (тот же автор, глава 12), где источником наиболее востребованных кадров для высокотехнологичного бизнеса служит... армия. Оказывается, срочная служба в технических подразделениях предоставляет не только необходимые компетенции, но что не менее важно - создает плотные профессиональные сети бывших сослуживцев, помогающие находить работу и вести собственный бизнес. Как показало исследование, образовательные стратегии выходцев из бывшего Советского Союза, центрированные, напротив, на университетском образовании, воспроизводятся уже во втором поколении и в известной мере объясняют их слабое присутствие среди программистов и руководителей стартапов. Для сравнения: более заметную роль представители обширной русскоязычной еврейской диаспоры играют в корпоративной IT-среде Бостона (Диана Курковски-Вест, глава 11). Полученное в СССР математическое образование дало им сравнительное преимущество на рынке труда программистов. Вместе с тем, по утверждению автора, советский опыт сформировал специфический профессиональный габитус, в силу которого эмигранты из Советского Союза редко занимают управленческие позиции в компаниях или начинают собственный бизнес. Наконец, механизмы и мотивы географической мобильности российских программистов рассмотрены в заключительной части книги на примерах диаспор в Великобритании (Ирина Антощюк, глава 10) и Финляндии (Любава Шатохина, глава 13).

Так, упомянутые выше кейс-стади крупными мазками рисуют широкую панораму «постсоветских ІТ-экосистем», включающую руководителей стартапов и других IT-компаний, программистов, работающих по найму в России и в эмиграции, академических исследователей, университетских преподавателей и энтузиастов компьютерного образования, наконец, «гражданских хакеров» (программистов, участвующих в разработке приложений в рамках разного рода гражданских инициатив: Ксения Ермошина, глава 3). Попытка представить более целостную картину основных тенденций развития этого разнородного поля, которые так или иначе рассматривались в разных частях рецензируемой книги - от институционализации государственной политики и развития образования в этой сфере до оценки иммиграционных трендов и феномена «утечки мозгов», - предпринята Дмитрием Жихаревичем в главе 9. Однако приведенные здесь количественные показатели представляются довольно случайными и не позволяют в достаточной мере контекстуализировать представленные кейсы. Впрочем, указанный недоста- 
ток легко объясняется выбранной в рамках проекта исследовательской стратегией. Что более существенно, книге в целом (не считая некоторых перекрестных отсылок и более или менее удачных попыток локальных обобщений в отдельных главах) не хватает дополнительного интеллектуального усилия по обобщению различных кейс-стади, предлагающих, как мы увидели выше, широкий разброс тем и локализаций. Создается впечатление, что разнообразие материала в какойто момент вышло из-под контроля, существенно раздвинув изначально запрограммированные рамки и задачи проекта. Пусть указанная проблема (равно как и не столь многочисленные, но от этого не менее досадные фактические ошибки) останется на совести кураторов проекта и по совместительству редакторов книги, не являющихся, впрочем, специалистами по советской и постсоветской истории науки и технологий. Вместе с тем открытость «финала» как бы приглашает к новым исследованиям как сам коллектив авторов книги, так и их возможных коллег в России и за ее пределами.

\section{СПИСОК ЛИТЕРАТУРЫ}

Бычкова, Ольга, Борис Гладарев, Олег Хархордин и Жанна Цинман. 2019. Фантастические миры российского хай-тека. СПб.: Издательство Европейского университета в Санкт-Петербурге.

Tatarchenko, Ksenia. 2013. "A House with the Window to the West: The Academgorodok Computer Center (1958-1993)." PhD dissertation, Department of History, Princeton University.

Yurchak, Alexey. 2002. "Entrepreneurial Governmentality in Postsocialist Russia: A Cultural Investigation of Business Practices." Pp. 278-325 in The New Entrepreneurs of Europe and Asia: Patterns of Business Development in Russia, Eastern Europe and China, ed. by Victoria E. Bonnell and Thomas B. Gold. Armonk, NY: M. E. Sharpe. 